\title{
An Accreditation Exhibit Repository for Higher Education Institution
}

\author{
Romulo L. Olalia Jr. \\ San Carlos College \\ Mabini St. San Carlos City 2420
}

\author{
Alfie V. Bugayong \\ San Carlos College \\ Mabini St. San Carlos City 2420
}

\begin{abstract}
This project study aimed to develop a solution that will integrate the latest ICT technologies, carefully planned policies, procedures and dedicated people to design an accreditation exhibit repository for Higher Education Institution. Specifically, it aimed to identify the problems encountered in the traditional exhibit preparation and management.
\end{abstract}

The researchers employed the descriptive-developmental research. This suits the situation since this kind of study focuses on the prevailing condition and assess changes over a period of time. For the software development, extreme programming where employed which is intended to improve software quality and responsiveness to changing stakeholder requirements.

The researchers used different elicitation techniques such as interview, observation, survey, document analysis, and downloading of supporting materials. These are utilized in order to gather important information to support the project. There are different tools used to analyze gathered data such as use case diagram, entity-relationship diagram, database schema, sitemap, Ishikawa diagram (cause-and-effect diagram) and some statistical tools such as the use of frequency count and percentage.

With the preparation and management evidences, the following problems were discovered: exhibits are presented in different sizes, kinds and formats; there is a large amount of evidences to be gathered; consolidation of exhibits from different sources and keeping all of its versions in-tack; duplication of evidences. Evidences might be needed in more than one sub-criteria and/or section; and accessibility of exhibits. Not all evidence can be accessed by anyone.

The developed Accreditation Exhibit Repository for Higher Education Institution will help solve the problems identified in the preparation and management of exhibits for accreditation purposes. The system was tested on its acceptability and it was found out that it may handle the rigorous task of handling accreditation exhibits during and after the accreditation visit by the accrediting body.

\section{Keywords}

Accreditation, accreditation exhibit, repository, document management

\section{INTRODUCTION}

As many people who work in an office can attest, paper is ubiquitous. While buried under piles of memos, reports, to-do list, forms and manuals, paper's services seem indispensable, yet the paper itself seems to be a great burden. Quite likely, both impressions are true. [1]

TechTarget.com defines document as "a record or the capturing of some event or thing so that the information will not be lost. Usually, a document is written, but a document can also be made with pictures and sound. A document usually adheres to some convention based on similar or previous documents or specified requirements. [2]

A document is a form of information. A document can be put into an electronic form and stored in a computer as one or more files. Often, a single document becomes a single file. An entire document or individual parts may be treated as individual data items.

The ability to document processes, place or fill forms, manage human resources, communicated between employees, store information, edit document and protect oneself or the company can be the core of business operations. Historically, providing these services required the use of paper. Without this, it would very difficult to conduct business.

Document management can also be costly when unmanaged. According to a compilation of statistics regarding paper usage reveals that an average office worker uses more than 10,000 sheets of paper per year, which is about 20 reams of paper per employee. With an average of Php 120.00 per ream, it will be a Php 2,400 annual cost per employee. The cost of the paper is only about $10-11 \%$ of the life cycle cost of that paper. The main cost of paper usage fall into copying, storage and retrieval of that paper, with copying cost at $33 \%$ and distribution cost at $56 \%$. This estimate does not include printing cost.

Of all the pages that get handled each day in the average office, $90 \%$ are merely shuffled. The average document gets copied 19 times wherein it cost Php 47 per document. Companies spent Php 50 in labor to file a document, Php 1,200 in labor to find a misfiled document, and Php 3,500 in labor to reproduce a lost document. It is estimated that $7.5 \%$ of all documents get lost, $3 \%$ of the remainder get misfiled. Professionals spend $5-15 \%$ of their time reading information, but up to $50 \%$ are looking for it. There are over 2 trillion paper document in the Philippines - growing at a rate of $22 \%$ per year. [4]

In an educational institution where quality education is not an option but a tradition, a notable scenario can be observed during accreditation of academic programs. One of the researchers, being the chairman of Section/Area V which comprises of computer laboratories, speech lab and physics 
laboratory, he has personal understanding on the difficulty of producing and duplicating exhibit. Even if a program has undergone several accreditation visit and acquired accreditation, documentary evidences are still difficult to consolidate and person that should be responsible for such documents are difficult to identify since they are passing the responsibility to just like everyone. Updating and consolidation of such updates are difficult because two copies of the same document might exist and update can be either both on the two copies. This makes copies different from the other.

Looking deeper on the situation, documents from different sources are duplicated as the need for exhibit arises in different section of accreditation. Duplication requires papers, electricity, consumables for the copier, and time of the employee who did the photocopying. Folders and clips are also used. Cost rises as the need arises. Having two different storage locations require separate office space, separate manpower to manage it, separate security measures to implement, and separate accessibility level.

To multiply these problems even further, same documents will be likely be needed by other department during their accreditation and/or reaccreditation. Isolated problems might also exist on each department like misfiling of documents, lack of office space due to storage of other papers, insufficient searching strategy, and some accessibility issues on who can only see, search and duplicated documents.

The given scenario is only one of those occasions wherein we need to retrieve, reproduce and gather data. Things are tend to be overlooked which are of little value at the time being like ordinary paper works. However, when things are getting bulky and difficult to manage, that will be the time that the need for managing those resources will be realized and the task can be more difficult and frustrating.

Idealistic as it seems, but having a centralized accreditation exhibit repository helps saves time and space, reduce cost, improve operational efficiency and provides security for all documents. [4]

\section{BACKGROUND}

In the last few years, technology has advanced rapidly, enabling significant changes in the ways companies communicate with each other. Modern communication methods such as email, internet forms and digital video and sound files, accelerated business processes and gave the term 'document' a new definition. Today, many companies rely heavily on electronic business documents.

As with the paper documents, scanning, storing, retrieving and accessing electronic documents requires security with prompt access for authorized users. To optimize process and add value to their services, companies need an integrated archiving solution that lets them manage documents in a secure and structured manner. [5]

The Accreditation Exhibit Repository for Higher Education Institution is a digital document repository that manages the scanning, storing, tagging, archiving and retrieving digital documents. BusinessDictionary.com defines it as "an electronic system designed to organized and manage documents. These documents are usually organized with software, which provides the user with the ability to access, modify, and centrally store the documents. Repository handles tedious tasks such as archiving, distribution, and creation of documents." [6]

A study by Coopers and Lybrand, as restated by a study of PLDT [7], shows statistics on the cost of paper spent in a typical organization. Of all the pages that get handled each day in the average office, 90 percent are merely shuffled. The average document gets copied 19 times wherein it cost Php 47 per document. Companies spent Php 50 in labor to file a document, Php 1,200 in labor to find a misfiled document, and $\mathrm{Php} \mathrm{3,500} \mathrm{in} \mathrm{labor} \mathrm{to} \mathrm{reproduce} \mathrm{a} \mathrm{lost} \mathrm{document.}$ Estimated, 7.5 percent of all documents get lost, 3 percent of the remainder get misfiled.

Same study of PLDT provides a fact-full comparison between papers filing system versus document management system. On paper filing $7.5 \%$ of all document get lost and 3\% of the remainder get misfiled. Missing documents can take up to 10 times the amount of time to retrieve as properly filed documents. In document repository, once a document is in the system, it can never be lost. With proper backup procedures in place, disaster recovery can occur very quickly. Document collaboration or multi access is impossible with paper based filing unless copies are made. In document repository, since documents are digital, multiple users can access the same file at the same time. On average, $50 \mathrm{~kb}$ is required per black and white digital document. This calculates to around 20,000 pages per GB or 1 million pages per $50 \mathrm{~GB}$.

Despite of advancement in technology and sophisticated manual business process, the volume of paper that hits a typical company is overwhelming. And the problem is even worse in education institution that stack-file record of students, memorandum, business correspondents, credentials, purchase orders and many more. "Paper is extremely cumbersome and unwieldy," says Kay Bross, senior public key infrastructure specialist for Procter and Gamble. "Plus it's expensive and time-consuming to manage". [8]

In response to this, Miles Mathieu says that "By eliminating paper, information technology proponents believe businesses can cut exorbitant costs and boost efforts to protect the environment. Computer-based business systems would also vastly improve office efficiency and effectiveness by eliminating certain 'face-to-face' steps required in the antiquated paper-based office environment." [9]

Embracing a new process is like leaving your comfort zone. One of the difficulties in introducing an automated system wherein papers reduced their numbers and you will be operating scanners and computers. Annoying at first and can be tire-some after several days. A similar scenario was encountered by Procter and Gamble. Although the software installation and system integration phases have gone smoothly, $\mathrm{P} \& \mathrm{G}$ had to face some of the challenges that pop up with any new IT initiative. The biggest hurdle has been getting employees particularly those who are attached to paper - to accept the new workflow and learn how to use a new application. [10]

According to Bross as cited in Greengard, "Not everyone initially trusts the system, and not everyone wants to change the way they work. We have had to face some changemanagement issues and provide training". While this is true, people are trainable. Discussions on the system and abrupt assistance during training and implementation will make them at ease. Heather Sarantis in his Business Guide to Paper 
Reduction, "Training the point people in how to support paper reduction goals is an important investment because they can then train other people in their department. Training may focus on general education such as why reducing paper is important or specific skills such as sharing documents. Additionally, new employees need to be educated to sustain the momentum".

Furthermore, document management system needs functionality to search a document by title, author and tags. Because all information about the document is saved into the database system, this searching functionality can be performed by a database management system. The major concern is the support for free text searches [11]. Path Selinger (IBM Fellow and VP Data Architecture \& Technology) believes that less than 15 percent of the world's data structured. In order to deal with large amount of unstructured data, document repository should offer querying support for plain text contents through pattern matching. SQL Select command can achieve this goal and should be implemented in document repository. By providing in-content searching, the developed repository exceeds the normal querying process.

\section{DISCUSSION OF FINDINGS 3.1 Problems Encountered During Exhibit Preparation}

Accreditation assures the quality of instruction, appropriateness of methodology, caliber of faculty and sustainability of resources and facilities of any given educational institution. This also assures that students will have the best, if not, better training to succeed in their educational endeavor.

However, being granted as an accredited educational institution means a lot of hard work, costly and timeconsuming. During preparations of evidences, problems may be encountered. These can vary in formats, size, availability, and accessibility. During preparation, the following problems are met:

\subsubsection{Exhibits are presented in different kinds and sizes.}

Most of the exhibits are in printed form such as reports, forms, correspondence, marketing materials, posters, banners, certificates, diploma, floor plan, pictures, blueprints, newspapers, magazines, journals, books, class records, tarpaulins, banners, brochures, charts, manuals, projects, syllabus, lecture notes, notice, memorandum, minutes, payroll, inventories, licenses, contracts, financial statements, registrations, daily time record, slips, official receipt, voucher, purchase order, assignment papers, and bills. This printed evidences also comes in different size such as letter, legal, A4, A3, 8.5 X 11" and other custom sizes.

Evidences can also be physical and material. These can be building or structure such as classrooms, offices, resource centers, library, laboratories, indoor game facilities, outdoor game facilities, audio-visual rooms, gymnasium, canteen, clinics, façade, hallways, security facilities, conference room, chapels, training center, comfort rooms, emergency facilities, sheds, pathways, relaxation area, parking spaces, water facilities, drainage and dormitory/staff house. Aside from buildings and structure, equipment and furniture can also be considered as exhibit in the accreditation. It can be computers, air conditioning facilities, ventilation, multimedia equipment, science laboratory equipment, printing equipment, generators, lightings, chairs, tables, appliances, and automobile. Other materials such as storage disc, video, slide presentation, spreadsheets, digital documents and supplies are considered as evidences.

\subsubsection{Vast amount of evidences}

There are evidences that are enormous in size. Sample of which are vouchers, enrolment forms, lecture notes and grade sheets. All of these things can be considered as exhibits and therefore have the right and chance to be included in the final evidences. Some of these may be required in more than one criterion thus, duplication is unavoidable.

\subsubsection{Consolidation of evidences}

Accreditation instruments are divided into different sections. These sections have its assigned committee which is compose of chairman and members. During gathering of evidences, two or more sections may need same documents. In this case, all of the section committee will request (sometimes needs a formal letter especially those sensitive documents) the same document at a single person or department. Different version or update of that document may also exists which sometimes makes the integrity of evidence in question. In situation wherein updated version of the document being exhibit is created during accreditation, all of the exhibited documents will automatically be outdated. Consolidation of such evidences will again require another set of request.

\subsubsection{Duplication to evidences}

It can be assumed that most programs in an educational institution want to be accredited. Since accreditation is per program and per level status, evidences that belong to the core section of the survey instrument are needed in every accreditation. This requires large amount of duplication just to complete the evidences required for the core section of every accreditation.

\subsubsection{Accessibility of needed evidence}

It can be that most of the evidences can be shared easily to other committee and reproduction can be done anytime however some documents are sensitive enough that only authorized person can look on it. Requesting of such documents may need written request and approval from proper authority. Moreover, once evidence was already exhibited, it may be almost impossible to allow or restrict it to other people, may it be a member of the committee or not.

\subsection{Features of the Accreditation Exhibit Repository}

The developed repository is designed specifically to address the problems encountered during preparation of accreditation exhibit. Each feature are systematically designed to answer each challenges faced by committee and stakeholders. The following are the major features of the system:

\subsubsection{Support for different exhibit format}

Since evidences can be of any form, saving it in digital form is another thing. These evidences can be grouped into five (5) classifications. These are PDF or doc, image, audio, video, and slide presentation.

Those documents that are of ordinary form whose raw source is from word processing software, spreadsheet, desktop publishing and some digital imaging software will be converted into portable document format or PDF. Most of 
today's application programs support exporting to PDF format. PDF was developed by Adobe Systems and is now an open standard for electronic document exchange maintained by the International Organization for Standardization. [12] It supports text, images, graphs and even online forms.

Evidences that have large number of pages such as books, manuals, and journals will not be converted to digital format entirely. Front page and/or preliminary pages will be scanned and save in PDF formats however, summary or overview can be included during uploading. Location to where it can be found and the concern person to ask will also be stored so that in case further verification is required, it can be located immediately and can be address to the concern person.

Large prints such as floor plan, evacuation plan, building plan, banners, posters, charts and other marketing media will be treated differently. If digital copy of the evidence is available, it can be reduced in size and converted to PDF or image. Large prints with no digital copy that can be reduced in size using duplicator or photocopier will be reprinted in small form, scanned and save it into image or PDF file. If the evidence is large enough for photocopier to reduce, pictures of it will be taken. These include tarpaulins, banners and organizational charts.

Evidences for building structures, facilities, apparatus, materials and equipment will be taken in a form of images. Same procedure will be done for exhibits for actual class instructions, social orientation, community involvement, student services and personnel services. It should be noted that these areas also has evidences that are paper-based and can be easily scanned and uploaded.

Laboratory, specifically speech lab has several audio files use for class activities. All audio files can be uploaded. Should the committee decided not to upload all audio materials or should an audio file exceed an agreed maximum size of file, it's title, description, location and person concern will be stored in the repository.

Some evidences in instructions include short clips and even full-length movies. While this format is supported by the repository, there will be consideration on the size of the file. In this case, the title, description, location and person concern will be stored in the repository.

Categorizing evidences in these five classifications enables the developed accreditation exhibit repository store every evidences needed for the accreditation. The following data formats are supported by the system: pdf, xls, doc, ppt, mp3, mpeg, jpg, gif and png.

\subsubsection{Exhibit Management}

Exhibits are viewed based on the accessibility level of the user. Menus are provided depicting the corresponding area for each exhibit, dynamically. The over-all chairman can access all exhibits in all areas of his accreditation. Aside from the convenient area menu, the main dashboard (Figure 1) has a search option for searching exhibits and request management module for requesting and approving of access request to a particular exhibit.

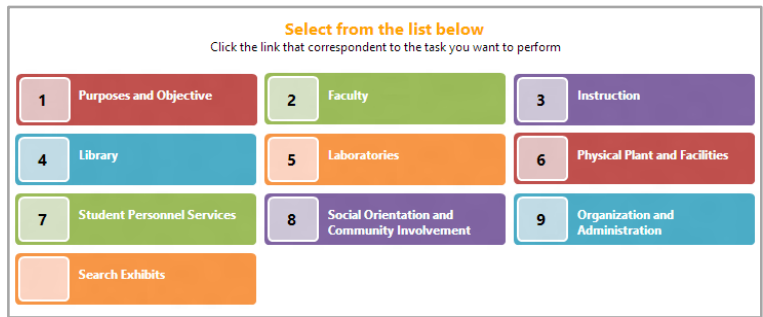

Figure 1 - Available options for the over-all chairman.

Area chairman and members are confined to the area they are assigned to. They cannot access any other area.

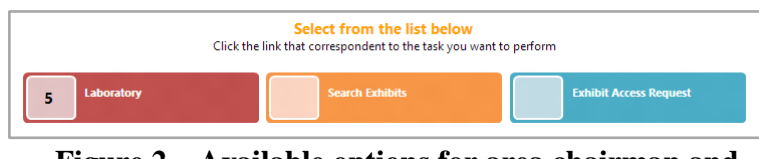

Figure 2 - Available options for area chairman and members.

Clicking a particular area will open its list of criteria. Link for adding an exhibit are dynamically created. The module showing the exhibit in a particular criteria has the option view the actual exhibit, view the exhibit details and delete it. Committee can decide if a certain document be deleted from the exhibit (Figure 3). However, if a document is exhibited in a certain criteria, it cannot be deleted.

\begin{tabular}{|c|c|}
\hline Options & Title \\
\hline$x \notin \pi$ & Picture of Outlet \\
\hline $\begin{array}{l}\text { Delete ex } \\
\text { Adrarv }\end{array}$ & $\begin{array}{l}\text { hibit } \\
\text { WExnibit Add Existing Exhibit }\end{array}$ \\
\hline
\end{tabular}

Figure 3 - Delete option for the exhibit management

Adding an exhibit can be of two ways: adding a new exhibit or adding an existing exhibit. Figure 2 shows the module for uploading a new exhibit. Adding an existing exhibit from request has different process. Once the request for access for a particular exhibit has been approved, viewing its details gives the user an option to assign the exhibit to a criteria (as shown in Figure 4).

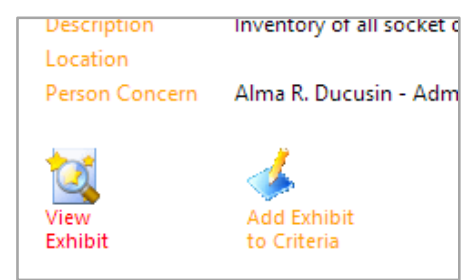

Figure 4 - "Add Exhibit to Criteria" link for assigning an exhibit to a criteria.

The "Add an Exhibit from Other Area" form will show (Figure 5) which allows you to confirm the adding of exhibit. Exhibit descriptions and accessibility cannot be define here because the owner of the file the right to do so. However, title of the exhibit can be change since document can be of different title from other sections. 


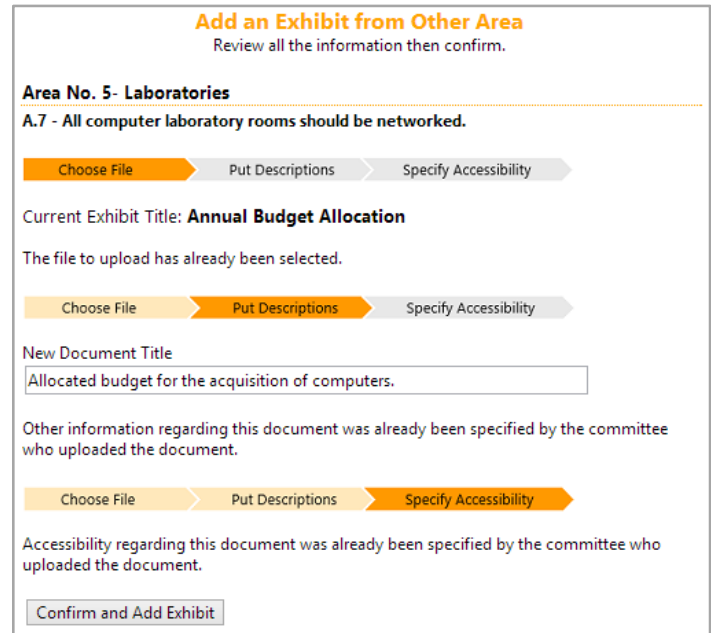

Figure 5 - "Add an Exhibit from Other Area" form.

\subsubsection{Title-based, Description-based and in- content Searching}

Sections may contain hundreds of exhibits. These exhibits should be manage properly and therefore needs a mechanism for fast searching. The developed repository supports three levels of searching: title-based, description-based and incontent searching.

Title-based searching is the fastest search mechanism because it only searches through the titles of evidence through a keyword or keywords on the title.Description-based and tag searching is almost the same as title-based except that the program search on the description of the exhibits.

A more in-depth searching can be done through in-content searching. This search feature searches the content of the actual document (assuming that it is a searchable evidence like PDF files) (Figure 6).

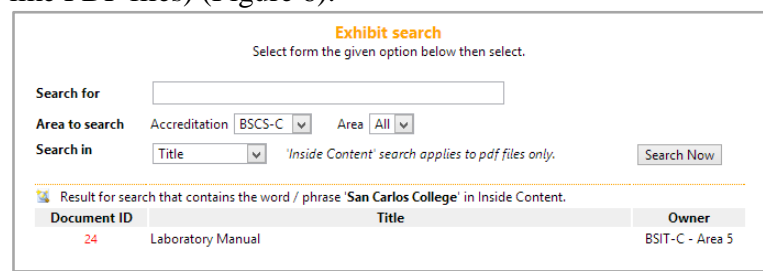

Figure 6 - Search module showing result for in-content search.

\subsection{Access granting and restriction}

One of the most promising features of the system is granting access and restriction. Accessibility can be default or requested. Below is an overview of how exhibits are access and/or restricted by and from users:

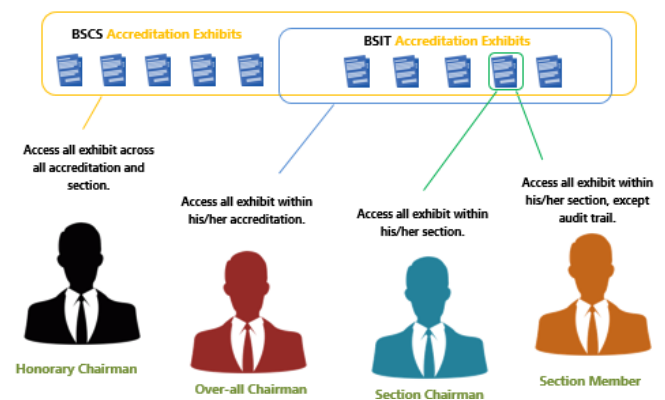

Figure 7 - Accessibility by different users.
The Honorary Chairman can access all information including sections, criteria, committee and exhibits across all accreditation. The over-all chairman has access to all evidences underlying an accreditation. He / She can grant access to any committee requesting for such. Sections committee has absolute access to their area evidence. The Section Chairman can view the audit trail for the section while section member cannot.

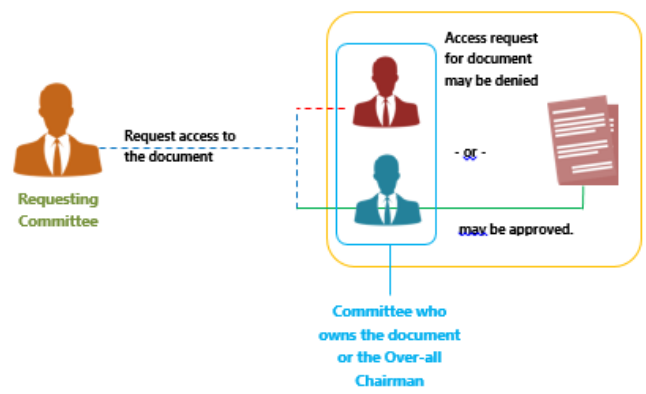

Figure 8 - Overview of the access-requesting for existing exhibits.

Should an exhibit be used across different sections, policies will be observed. There are there ways to gain access to an existing document. First, if the exhibit belongs to a common section. Second, if the exhibit was tagged as it can be access by all committee during adding of new exhibit. Finally, if a committee request an access to an existing and restricted exhibit from another section. Below is an overview how to request an access to an existing exhibit:

The committee can search, view, upload, update, and grant request of access on their evidences. Should a committee wants to access other section evidence aside from theirs, a request will be made to the concern committee chairman.

Once a request has been placed, the committee chairman will view the request and may decide if it will be granted or denied (Figure 10).

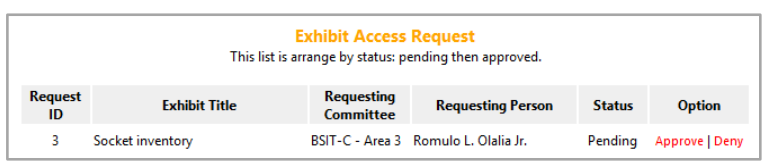

Figure 9 - Page for approving or denying a request for access.

\subsection{Browser-based and Multi-platform}

The developed repository is a browser-based program that takes advantage of some of the most popular and open source technologies. It is developed using different client-side language such as XHTML for the foundation of web pages, cascading style sheets (CSS 2.0) for the styles, format and layout of the pages, javascript for interactivity and validation, and JQuery for some special effects. Server-side technologies include Hypertext preprocessor (PHP) for interacting with the database, MySQL Community Server for the storage of records and Apache Server to manage all the services needed.

Since the program is browser-based, any device or a computer that has web browsers, irrespective of its operating system can be used to access the repository. The program is stored and configure in intranet setting but can be easily uploaded and configured in internet environment when needed arises. 


\subsection{Multi-user}

The repository supports four kinds of users. These are the over-all chairman, honorary chairman (admin), committee chairman and members (both of which can access evidence on their own section). The repository provides a unified login module for all system users.

\subsection{Secure}

One of the features of the repository is the ability to automatically $\log$ all activities done within all processes pertaining to managing accreditation exhibit. Audit trail can be used if any questionable activities happen within the system or if the user wants to know particular activities done by the committee. Figure 10 shows list of activities done by users in the system.

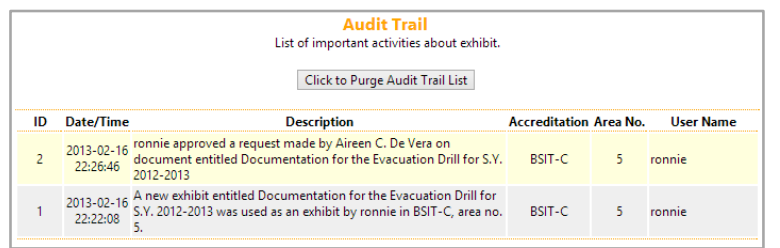

Figure 10 - Audit Trail of the repository.

The repository also employs a simple backup and backup download procedure. Should there be any uninvited problems regarding file storage, repository backup can be easily backup and copied to and from the local intranet server.

\subsection{User-Friendly}

User can be of different age, gender, educational attainment and perceptions and the system should therefore cater to these users. The program employs different features that will make the user at ease with all its functionality and module.

Every page and modules has sitemap located atop the web pages just after the banner (Figure 11). This helps the user know where he/she is in the hierarchy of modules. She/he can immediately switch back to the modules wanted by clicking on the link.

- Site Map: Main > Exhibits > Area Exhibit List > Manage Exhibits

Figure 11 - Sitemap of the "manage exhibits" page.

Each module also generous amount of information, hints and notes to make the user not to feel odd when using the system (as shown in Figure 12).

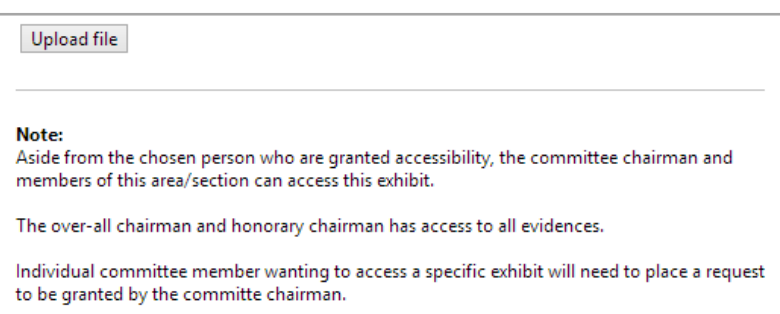

Figure 12 - Footnotes when uploading a new exhibit

The site also uses graphical progress indicator, to let the user know where he is on the process and how long will that process go.

\section{Choose File $>$ Put Descriptions $>$ Specify Accessibility}

Figure 13 - Graphical progress indicator

\section{EVALUATION}

Survey forms are prepared for the acceptability test. Questions are grouped by into different dimensions. These are security, reliability, performance, maintainability, availability and user interface. Each of the sections is represented by one (1) person. The over-all chairman is also included in the survey. The total number of respondents is ten (10) in every accreditation committee. Since there are four (4) programs (BSIT, BSCS, BSEd, and BSEE) with different accreditation level and most of the member of a committee are also member of other program's committee, the total no. of respondents is 21.

\section{Result for Interface-related questions}

Table 1 shows the result for the survey for the interfacerelated questions. These questions intends to find out how the stakeholders feel about the interface. This is important so as to adjust the layout until the stakeholders are satisfy working with it.

Table 1 - Summary of the acceptability test for interface-related dimension.

\begin{tabular}{|l|c|c|}
\hline \multicolumn{1}{|c|}{ Questions } & $\begin{array}{c}\text { Frequ } \\
\text { ency } \\
\text { Count }\end{array}$ & $\begin{array}{c}\text { Perce } \\
\text { ntage }\end{array}$ \\
\hline $\begin{array}{l}\text { Same theme is applied on all modules } \\
\text { and main switch board. }\end{array}$ & 21 & $100 \%$ \\
\hline Uses at most 3 color combinations. & 21 & $100 \%$ \\
\hline $\begin{array}{l}\text { Gives users feedback for accomplished } \\
\text { task and errors. }\end{array}$ & 21 & $100 \%$ \\
\hline $\begin{array}{l}\text { Provides site map and menus for easy } \\
\text { navigation }\end{array}$ & 21 & $100 \%$ \\
\hline Uses jargon-free terms for wordings. & 20 & $95 \%$ \\
\hline Provides description for every module. & 21 & $100 \%$ \\
\hline
\end{tabular}

The respondents answer the questions affirmatively except for question number 5. Generally, the respondents agrees that the interface is friendly-enough to be used by the user. They appreciated how the pages are applied with same theme, the easy navigation and visual guide for progress and menus.

\section{Result for security questions}

Security related questions include questions that justify that the system implements enough security to protect its users and all documents stored in the repository. The following table is the summary for security related questions.

Table 2 - Summary of the acceptability test for security dimension.

\begin{tabular}{|l|c|c|}
\hline \multicolumn{1}{|c|}{ Questions } & $\begin{array}{c}\text { Frequ } \\
\text { ency } \\
\text { Count }\end{array}$ & $\begin{array}{c}\text { Perce } \\
\text { ntage }\end{array}$ \\
\hline $\begin{array}{l}\text { Allows / restrict computer from using } \\
\text { the system. }\end{array}$ & 21 & $100 \%$ \\
\hline Provides log-in module for users. & 21 & $100 \%$ \\
\hline $\begin{array}{l}\text { Uses encryption on typed values in } \\
\text { textboxes during login. }\end{array}$ & 20 & $95 \%$ \\
\hline Allows user to change their password. & 21 & $100 \%$ \\
\hline $\begin{array}{l}\text { Documents can be restricted from other } \\
\text { user. }\end{array}$ & 21 & $100 \%$ \\
\hline $\begin{array}{l}\text { Admin user can access all information } \\
\text { regarding accreditation. Users can } \\
\text { access all information in their respective } \\
\text { sections. }\end{array}$ & 21 & $100 \%$ \\
\hline $\begin{array}{l}\text { Submitted information is transported } \\
\text { securely between server and clients. }\end{array}$ & 19 & $90 \%$ \\
\hline Provides audit trail. & 21 & $100 \%$ \\
\hline
\end{tabular}


This summary shows that users "feel" and "know" that there is a sense of security covering all the entire process. Most of the respondents also appreciate and greatly commended how the system handles requesting and granting access to certain documents.

\section{Result for reliability questions}

Questions on reliability dimension focuses on how much the user can depend on the system in all the process involves within. This also includes questions regarding contingency measures in case unavoidable incident happens. The following is the result for the survey:

Table 3 - Summary of the acceptability test for reliability dimension.

\begin{tabular}{|l|c|c|}
\hline \multicolumn{1}{|c|}{ Questions } & $\begin{array}{c}\text { Frequ } \\
\text { ency } \\
\text { Count }\end{array}$ & $\begin{array}{c}\text { Perce } \\
\text { ntage }\end{array}$ \\
\hline $\begin{array}{l}\text { Links are working and will bring user to } \\
\text { the right module. }\end{array}$ & 21 & $100 \%$ \\
\hline $\begin{array}{l}\text { Assures user that a task has been } \\
\text { successfully done. }\end{array}$ & 21 & $100 \%$ \\
\hline Buttons functions accordingly. & 21 & $100 \%$ \\
\hline Includes backup module. & 21 & $100 \%$ \\
\hline Search module functions as stated & 21 & $100 \%$ \\
\hline $\begin{array}{l}\text { The system is able to handle multiple } \\
\text { concurrent connections. }\end{array}$ & 21 & $100 \%$ \\
\hline No page errors appeared. & 20 & $95 \%$ \\
\hline
\end{tabular}

Overall, the summary suggests that all of the respondents rely on the system on all the modules included in the system. There are also no comments or suggestion given by the respondents.

\section{Result for performance questions}

Questions on the performance dimension are based on actual execution of the program in a time-bounded scenario. During testing, the respondents uses two computers: a laptop computer (Lenovo with dual core processor $1.87 \mathrm{Ghz}, 2 \mathrm{~Gb}$ RAM, Intel GMA graphics card and 500Gb HDD) which is connected via wireless connection and desktop PC that acts as server (Intel i3 2.6Ghz, 2Gb RAM, 1GB nVidia graphics card and $500 \mathrm{~Gb} \mathrm{HDD})$. The following is the result for the survey:

Table 4 -Summary of the acceptability test for performance dimension

\begin{tabular}{|l|c|c|}
\hline Questions & $\begin{array}{c}\text { Frequ } \\
\text { ency } \\
\text { Count }\end{array}$ & $\begin{array}{c}\text { Perce } \\
\text { ntage }\end{array}$ \\
\hline Page load at most 5 seconds. & 21 & $100 \%$ \\
\hline $\begin{array}{l}\text { Saving, searching and updating of } \\
\text { records are done at most 10 seconds. }\end{array}$ & 21 & $100 \%$ \\
\hline $\begin{array}{l}\text { Immediately gives feedback during } \\
\text { wrong entry on forms before actually } \\
\text { sending it to the server. }\end{array}$ & 21 & $100 \%$ \\
\hline
\end{tabular}

All questions got "yes" answers from the respondents which mean they are happy with the performance of the system. They also commended that the program executes fast during the test.

\section{Result for maintainability questions}

Dimension for maintainability includes questions regarding how the system can be maintain and manage easily by technical personnel or even employee with average knowledge of computer operation. The following is the result for the survey:

Table 5 - Summary of the acceptability test for maintainability dimension.

\begin{tabular}{|l|c|c|}
\hline \multicolumn{1}{|c|}{ Questions } & $\begin{array}{c}\text { Frequ } \\
\text { ency } \\
\text { Count }\end{array}$ & $\begin{array}{c}\text { Perce } \\
\text { ntage }\end{array}$ \\
\hline $\begin{array}{l}\text { Technologies used are widely accepted } \\
\text { by industry. }\end{array}$ & 21 & $100 \%$ \\
\hline $\begin{array}{l}\text { Technologies used are open-source and } \\
\text { popular among online community. }\end{array}$ & 21 & $100 \%$ \\
\hline $\begin{array}{l}\text { Database software uses user-friendly } \\
\text { interface and can be used by any } \\
\text { number of registered user. }\end{array}$ & 21 & $100 \%$ \\
\hline $\begin{array}{l}\text { Codes have comments that explain a } \\
\text { statement or block of statement. }\end{array}$ & 20 & $95 \%$ \\
\hline
\end{tabular}

All the respondents answer "yes" in questions no. 1 to 3 and they personally believe that there is vast amount of information regarding the technologies used, its maintenance, coding instructions and manuals. They are also happy to know that these technologies are free.

\section{Result for availability questions}

Availability dimension includes questions regarding how accessible the system is to the user in terms of platform and device differences. The following is the result for the survey:

Table 6 - Summary of the acceptability test for maintainability dimension.

\begin{tabular}{|l|c|c|}
\hline \multicolumn{1}{|c|}{ Questions } & $\begin{array}{c}\text { Frequ } \\
\text { ency } \\
\text { Count }\end{array}$ & $\begin{array}{c}\text { Perce } \\
\text { ntage }\end{array}$ \\
\hline $\begin{array}{l}\text { Support cross-platform operating } \\
\text { system. }\end{array}$ & 21 & $100 \%$ \\
\hline Support cross-browser compatibility. & 20 & $95 \%$ \\
\hline $\begin{array}{l}\text { Viewable in other devices with } \\
\text { browser and intranet connection }\end{array}$ & 21 & $100 \%$ \\
\hline
\end{tabular}

The summary shows that availability of the system for access in other devices and platform is demonstrated well. Most of the respondents agree that the system showcased a feature, that is, it is readily available to authorized person within the coverage on an intranet. On the other hand, there is an issue on the border of a given image link with viewed in Internet Explorer. That error is however resolved immediately by removing the border of the image link.

This acceptability test conducted with the respondents which are the members of the accreditation committee clearly emphasized that the developed system has all the features, functionality and modules that satisfies the overall requirements of the respondents.

\section{CONCLUSIONS}

People tends to find ways how to make life and work easier. But making task easier needs a lot of hardship and dedication. In this study, different problems were observed. Surprisingly, stakeholders and committee are not aware that these problems even exist. It is fact and it should be dealt accordingly and with enough precaution and consideration to the situation, to the people and to the process itself. 
The Accreditation Exhibit Repository for Higher Education Institution was done to help managing and gathering accreditation exhibit easier. It serves as a backup of previous accreditation and a stepping stone and foundation for the next department who endeavor to make a program accredited. It implemented features systematically designed to answers all the drawbacks during the process and make it easier for the user to use and take advantage of.

The acceptability test conducted with the respondents which are the members of the accreditation committee clearly emphasized that the developed system has all the features, functionality and modules that satisfies the overall requirements of the respondents. With the average of $98.83 \%$ of the total questions given, they affirmed that with some few revisions, based on their suggestion, the developed system may then handle the rigorous task of handling accreditation exhibit during and after accreditation by any accrediting body especially those of PACUCOA. Now, school can focus what things that are more important.

\section{REFERENCES}

[1] Sarantis, Heather (2008). Business Guide to Paper Reduction. ForestEthics.

[2] Techtarget.com (n.d.). Definition of document. Retrieved August 10 ,

2012
[3] PLDT (2009). The Benefits of Having a Document Management System. PLDT AppFarm Organize.

[4] Omar, Monalisa and B (2008). Felda Document Management System. Universiti Teknologi Malaysia, 2008.

[5] BusinessDictionary.com (n.d.). Definition of Document Management System. Retrieved March2, 2013 http://www.businessdictionary.com/definition/documentmanagement-system-DMS.html

[6] Greengard, Samuel (2008). A Document Management Study: Procter and Gamble. Retrieved February 1, 2013 http://www.baselinemag.com/c/a/DocumentManagement/A-Document-Management-Case-StudyProctor-Gamble/

[7] Mathieu, Miles (2008). The Paperless Office: Accepting Digitized Data. Troy State University College.

[8] Wang, Chao (2008). CSSE Document Management System: Implementation and Usability Evaluation. Auburn University, Alabama.

[9] Adobe Systems (n.d.). About Adobe PDF. Retrieved March 2, 2013 http://www.adobe.com/products/acrobat/adobepdf.html 